\title{
Investigating of a wide range of concentrations of multi-walled carbon nanotubes on germination and growth of castor seeds (Ricinus communis L.)
}

\author{
Zahra Fathi ${ }^{1}$, Ramazan-Ali Khavari Nejad ${ }^{1}$, Homa Mahmoodzadeh ${ }^{2 *}$, Taher Nejad Satari ${ }^{1}$ \\ ${ }^{1}$ Department of Biology, Science and Research branch, Islamic Azad University, Tehran, Iran \\ ${ }^{2}$ Department of Biology, Mashhad branch, Islamic Azad University, Mashhad, Iran
}

Vol. 57, No. 3: 228-236, 2017

DOI: 10.1515/jppr-2017-0032

Received: October 27, 2016

Accepted: August 08, 2017

*Corresponding address: homa_mahmoodzadeh@yahoo.com

\begin{abstract}
Carbon nanotubes act as regulators of plant germination and growth and are able to change the morphology and physiology of plant cells. The castor plant (Ricinus communis L.) belongs to the Euphorbiaceae family and is a very important medicinal plant. The aim of this study was to investigate the effect of 10 different concentrations of multi-walled carbon nanotubes (MWCNTs) $\left(2,5,10,20,50,75,100,125,250\right.$ and $\left.500 \mu \mathrm{g} \cdot \mathrm{ml}^{-1}\right)$ alongside the control under laboratory conditions on the germination and growth of castor seedlings. The results demonstrated that the maximum percentage of germination $(96.7 \%)$ and relative germination percentage (100\%) were found in the concentrations of 50 and $100 \mu \mathrm{g} \cdot \mathrm{ml}^{-1}$, respectively, and the highest germination rate $(53.3 \%)$ and the mean germination time (4.6 days) was seen in the concentration of $75 \mu \mathrm{g} \cdot \mathrm{ml}^{-1}$. However, no statistically significant differences were found between the different concentrations in any of the germination factors. In the concentration of $100 \mu \mathrm{g} \cdot \mathrm{ml}^{-1}$, there was a significant increase in the seedling vigor index I (400) when compared with the concentrations of 5 and $10 \mu \mathrm{g} \cdot \mathrm{ml}^{-1}$. The maximum seedling vigor index II (11.3) was found in the concentration of $100 \mu \mathrm{g} \cdot \mathrm{ml}^{-1}$ and was significantly different from the control and all applied concentrations. The length of radicle in the 100 and $125 \mu \mathrm{g} \cdot \mathrm{ml}^{-1}$ had a significant increase when compared with the control and the concentrations of 10 and $50 \mu \mathrm{g} \cdot \mathrm{ml}^{-1}$. The maximum seedling length $(4.6 \mathrm{~cm})$ was seen in the concentration of $100 \mu \mathrm{g} \cdot \mathrm{ml}^{-1}$ where there was a significant increase with $10 \mu \mathrm{g} \cdot \mathrm{ml}^{-1}$. Moreover, in the $100 \mu \mathrm{g} \cdot \mathrm{ml}^{-1}$ concentration, the largest number of rootlets (8.6) was seen and when compared with the control and concentrations of 5,10 and $50 \mu \mathrm{g} \cdot \mathrm{ml}^{-1}$, there was a statistically significant increase. The maximum wet weight $(0.3 \mathrm{~g})$ and dry weight $(0.1 \mathrm{~g})$ of seedlings were obtained in the concentration of $100 \mu \mathrm{g} \cdot \mathrm{ml}^{-1}$ and when compared with the control, there was a significant increase. It was found that in all factors related to the growth of seedlings, the concentrations of 10 and 50 MWCNTs had an inhibitory effect on the response index. The MWCNTs concentration of $100 \mu \mathrm{g} \cdot \mathrm{ml}^{-1}$ was considered as the optimum concentration in the growth stage of castor seedlings.
\end{abstract}

Key words: MWCNTs, germination, growth, Euphorbiaceae, Ricinus communis

\section{Introduction}

Nanotechnology is a developing area in all fields of human life. This technology makes it possible to create and organize materials at atomic and molecular levels (Tiwari et al. 2014).

Over the past decade, significant progress has been made in studying the properties of nanomaterials and their application in many areas such as medicine, biology and agriculture (Nel et al. 2013). Plants possess most of the vital compounds for drought ecosystems and they can act as an important path for transmitting nanomaterials into the environment. They can also accumulate nanomaterials in the food chain (Tiwari et 
al. 2014). The effect of nanoparticles on various plant species can vary and depends on the vegetative stage of plants, the method and the duration of being exposed to nanoparticles as well as the size, concentration, the chemical compounds, superficial structure, solubility, shape and accumulation of nanoparticles. Considering the chemical and physical properties, the reaction of nanoparticles with a plant species differs in various stages of growth (Ma et al. 2010). Among all nanomaterials, carbon nanotubes, due to their physical and chemical properties such as length, diameter, atomic structure and impurities, have unique chemical, thermal, mechanical, electrical and flexible properties and they have been extensively researched (Tiwari et al. 2014). Carbon nanomaterials are utilized to greatly increase fruit and crops (Nel et al. 2013). Absorption of carbon nanotubes by plants is a new field in nano agriculture. Carbon nanotubes can change the morphological and physiological properties of plant cells (Pourkhaloee et al. 2011; Lahiani et al. 2013) and are thought to regulate plant and seedling growth (Khodakovskaya et al. 2012; Haghighi and da Silva 2014). Multi-walled carbon nanotubes (MWCNTs) are a kind of nanomaterial and due to their unique nanostructures and extraordinary properties such as high electrical conductivity, large and special area, significant thermal stability, they have been seriously taken into consideration in fundamental research and technological development (Milne et al. 2004). Synthesis of MWCNTs in low concentrations leads to increased corn seedling germination while high concentrations lead to reduced growth. Increased growth mainly occurs via improvement of water transmission by carbon nanotubes. These compounds can be useful for the improvement of water flow, plant biomass and essential concentrations of calcium and iron (Tivari et al. 2014). The castor plant (Ricinus communis L.) belongs to the Euphorbia family (Euphorbiaceae) and economically it is one of the most important flowering plants in the form of evergreen, bush or long tree, glabrous, having large, claw shaped leaves with two edges, 30-60 cm in diameter. This plant, either wild or cultured, is distributed throughout tropical regions mainly for oilseed (Mani et al. 2013; Prakash and Gupta 2014). The skin of the root and leaf of the plant have laxative properties. The boiled plant is useful for rheumatism, inflammation and neurological disorders. Moreover, based on traditional medicine, it is utilized for the treatment of warts, corns, tumors of the head and mammary glands. The activity of the plant is due to the presence of important chemical compounds, such as flavonoids, saponins, glycosides, alkaloids and steroids (Prakash and Gupta 2014; Khan and Sanwal 2015).

This study is the first to report the effect of a wide range of MWCNTs concentrations on the germination and growth of castor seedlings as a medicinal plant and shows that the treatment of medicinal plants such as castor with MWCNTs can increase the growth of seedlings.

\section{Materials and Methods}

Ricinus communis seeds were taken from the Pakan Bazr Company, Isfahan Province, Iran. Multi-walled carbon nanotubes were supplied by the Nutrient Company. MWCNTs were suspended in deionized water $\left(500 \mu \mathrm{g} \cdot \mathrm{l}^{-1}\right)$ and sonicated for $30 \mathrm{~min}$. Their hydrodynamic diameters were analyzed by dynamic light scattering (DLS), using a particle size analyzer (VASCO 3, Cordouan, Pessac, France) at $25^{\circ} \mathrm{C}$. The zeta potential of MWCNTs was determined with the Zetasizer NanoZS ZEN3600 instrument. The X-ray diffraction (XRD) pattern of MWCNTs is shown in Figure 1. The XRD measurement showed that the multi-walled carbon nanotubes which were used were made of carbon.

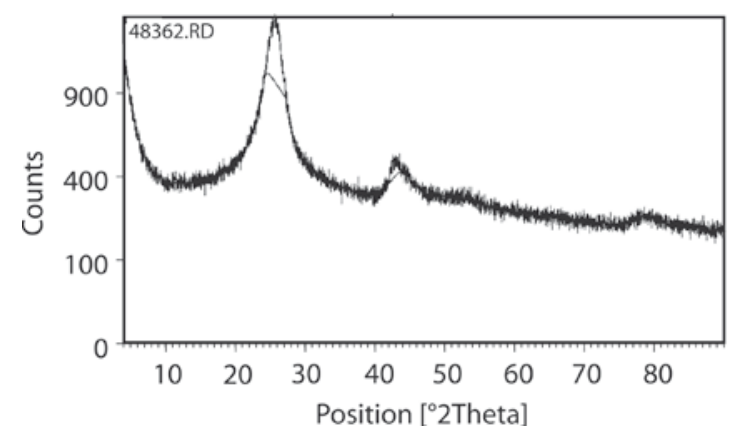

Fig. 1. The X-ray diffraction (XRD) pattern of multi-walled carbon nanotubes (MWCNTs)

\section{Experimental design}

In order to study the effect of different concentrations of carbon nanotubes on $R$. communis germination, a completely randomized design with four replications was employed. The experimental treatments included 10 concentrations $(2,5,10,20,50,75,100$, 125,250 and $\left.500 \mu \mathrm{g} \cdot \mathrm{ml}^{-1}\right)$ of carbon nanotubes and an untreated control (without carbon nanotubes). The experiment was conducted under laboratory conditions with natural light and an average temperature of $25 \pm 1^{\circ} \mathrm{C}$ at the Faculty of Science, Mashhad Branch, Islamic Azad University, Mashhad, Iran, in 2016. One hundred seeds, similar in size, were randomly selected and placed on moistened paper as four groups of seeds in Petri dishes (25 seeds on each Petri dish), and then $10 \mathrm{ml}$ of each concentration treatment was added to each Petri dish. For the control, only distilled water was added to the Petri dishes. Germination tests were performed according to the International Seed Testing Association. All concentrations of carbon nanotubes 
and the control were run at the same time and consequently under equal light and temperature conditions. The number of germinated seeds was noted daily for 7 days. Seeds were considered as germinated when their radicle was at least $1 \mathrm{~mm}$ long. In this study, we used the following germination parameters: germination percentage $(G P)$, relative germination percentage $(R G P)$, mean germination time (MGT), germination index $(G I)$, weighted germination index $(W G I)$, response index $(R I)$ and germination rate $(G R)$. Final percentage germination for each treatment was calculated after seven days. The germination index is based on the number of seeds that germinated and the germination rate (Figueroa and Armesto 2001; Bu et al. 2007a,b, 2008, 2009; Wu and Du 2008; Kandil et al. 2015).

$$
\begin{gathered}
G P=\frac{G N}{S N} \times 100, \\
R G P=\frac{G P \text { treatment }}{G P \text { control }} \times 100, \\
M G T=\sum_{i} G i \times \frac{i}{\sum_{i} G i}, \\
G R=\sum_{i}^{n} \frac{S i}{G i} \times 100,
\end{gathered}
$$

where: $G N$ - the total number of germinated seed, $S N$ - total number of seeds tested, $i$ - the number of days since the day of sowing, $n$ - number of days, $S i-$ the number of seeds germinated on day I, $G i$ - the days of germination.

Germination index $(G I)$ is a synthetic measure designed to reflect the synthetical germination ability including germination rate and germination numbers.

$$
G I=\frac{\sum(N-i) \times G i}{N \times G N} \times 100,
$$

where: $i$ - the number of days since the day of sowing, $\mathrm{Gi}$ - the number of seeds germinated on day I, $\mathrm{N}$ - the total number days of the experiment, GN - the total germinated seeds.

A weighted germination index (WGI) as described by $\mathrm{Bu}$ et al. (2007) was calculated with maximum weight given to the seeds germinating early and less to those germinating late.

$$
\begin{gathered}
W G I=[N \times n 1+(N-1) \times n 2+(N-2) \times n 3+ \\
\ldots+1 \times n 7] / N \times N,
\end{gathered}
$$

where: $n 1, n 2, \ldots, n 60$ are the number of seeds that germinated on the first, second, and subsequent days until the 7 th day, respectively; $N$ - the total number days of the experiment; $N^{\prime}$ - the total number of seeds placed in incubation.

Seed vigour is the sum of those properties which determine the potential level of activity and performance of the seed or seed lot during germination and seedling emergence (Kandil et al. 2015):

Vigor index I = GP $\times$ seedling length $($ root + shoot $)$,

Vigor index II $=G P \times$ dry weight

Response index $(R I): R I=1-(C / T)($ If $T>C)$ and $R I=(T / C)-1$ (If $T<C) ; R I$ ranges from -1 to +1 , with positive values indicating stimulation by the treatments and negative values indicating inhibition by them, relative to the controls. The absolute value of RI means the degree of inhibition and stimulation of aqueous extracts (Tang et al. 2008).

After an incubation period of 7 days, plumule and radical length of seedlings were measured using a ruler. In order for dry biomass to be weighed, the 7-day seedlings were first weighed; then, having been placed in an oven at $80^{\circ} \mathrm{C}$ for $48 \mathrm{~h}$, they were weighed a second time.

\section{Data analysis}

Significant differences for all statistical tests were evaluated at the level of $\mathrm{p} \leq 0.05$ with ANOVA. All data analyses were conducted using SPSS for Windows, Version 13.0.

\section{Results}

\section{Identifying the characteristics of carbon nanotubes}

Figure 2 illustrates how the size of MWCNTs was determined by a nanoparticle size analyzer. The highest number of nanotubes were in the range of 35 to 300 nanometers. The average diameter of particles was $91.3 \mathrm{~nm}$, the hydrodynamic diameter of particles was 45.7 and the distribution index of particles was 0.3 (Fig. 2). Zeta potential was $-26.26 \mathrm{mV}$ for MWCNTs (Fig. 3).

\section{The results of germination}

The results of our germination studies demonstrated that the effect of multi-walled carbon nanotubes on the germination indexes of castor seeds such as percentage of germination, relative germination percentage, germination rate, mean germination time and weighted index in all the concentrations used was not statistically significant different in comparison with the control 
A

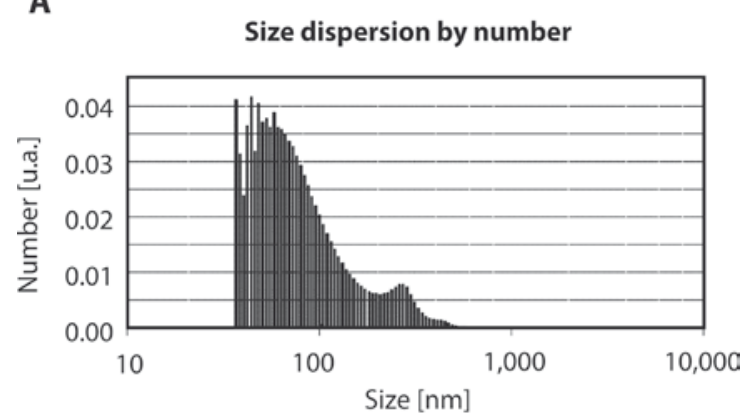

B

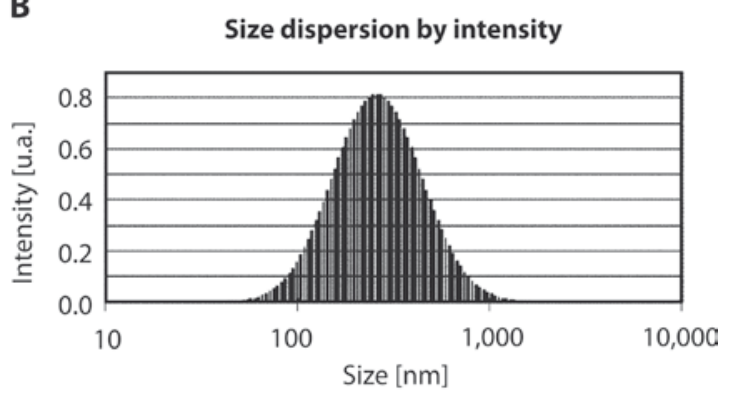

C

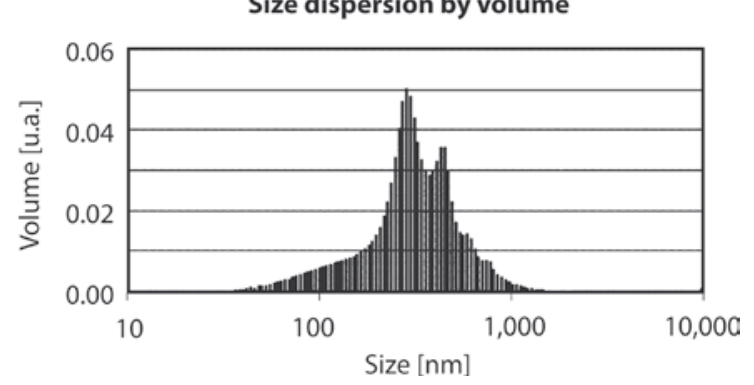

Fig. 2. Hydrodynamic diameter of carbon nanotubes determined by dynamic light scattering (DLS) and expressed as: A - number, $B$ - intensity percentage, $C$ - volume

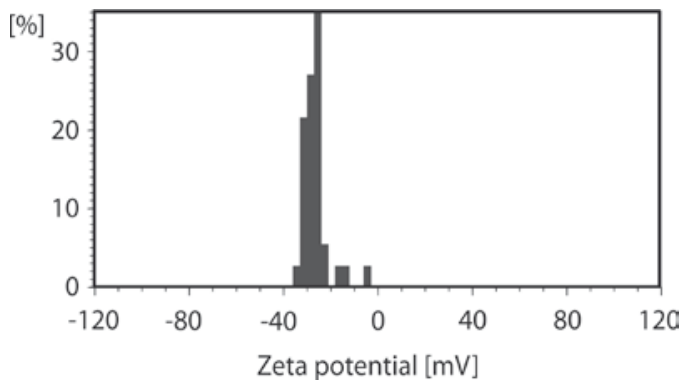

Fig. 3. Zeta potential of multi-walled carbon nanotubes (MWCNTs)

(Table 1). The highest germination index was seen in the concentration of $250 \mu \mathrm{g} \cdot \mathrm{ml}^{-1}$ which showed a significant increase in comparison with the concentration of $20 \mu \mathrm{g} \cdot \mathrm{ml}^{-1}$, but with the control and other concentrations, there was no statistically significant difference (Table 1).

The minimum length of rootlet $(0.75 \mathrm{~cm})$ was seen in the concentration of $10 \mu \mathrm{g} \cdot \mathrm{ml}^{-1}$, and the maximum length of rootlet $(1.36 \mathrm{~cm})$ was seen in the concentration of $100 \mu \mathrm{g} \cdot \mathrm{ml}^{-1}$. In comparison with the control and concentrations of 10 and $50 \mu \mathrm{g} \cdot \mathrm{ml}^{-1}$, there was a significant increase.

The plumule length of castor seedlings with carbon nanotube treatment was minimum $(1.9 \mathrm{~cm})$ in the concentration of $10 \mu \mathrm{g} \cdot \mathrm{ml}^{-1}$, while it was maximum $(3.3 \mathrm{~cm})$ in the concentration of $500 \mu \mathrm{g} \cdot \mathrm{ml}^{-1}$, although no statistically significant difference was seen.

The length of castor seedlings was maximum in concentrations of 100 and $500 \mu \mathrm{g} \cdot \mathrm{ml}^{-1}$ carbon nanotube treatments, while in comparison with the

Table 1. Mean value $( \pm \mathrm{SE})$ of germination percent $(G P)$, relative germination percent $(R G P)$, mean germination time (MGT), germination rate $(G R)$, germination index $(G l)$ and weighted germination index (WGI) for Ricinus communis seeds with different concentrations of multi-walled carbon nanotubes (MWCNTs)

\begin{tabular}{ccccccc}
\hline $\begin{array}{c}\text { Treatments } \\
{\left[\text { MWCNTs } \mu \mathrm{g} \cdot \mathrm{ml}^{-1}\right]}\end{array}$ & $G P$ & $R G P$ & $M G T$ & $G R$ & $G l$ & $W G l$ \\
\hline Control & $93.33 \pm 3.33 \mathrm{a}$ & - & $4.37 \pm 0.033 \mathrm{a}$ & $49.13 \pm 1.906 \mathrm{a}$ & $229 \pm 7.892 \mathrm{ab}$ & $2.95 \pm 0.108 \mathrm{a}$ \\
2 & $93.33 \pm 3.333 \mathrm{a}$ & $100 \pm 0.000 \mathrm{a}$ & $4.48 \pm 0.05 \mathrm{a}$ & $47.53 \pm 1.189 \mathrm{a}$ & $211 \pm 10.313 \mathrm{ab}$ & $2.95 \pm 0.124 \mathrm{a}$ \\
5 & $86.67 \pm 3.333 \mathrm{a}$ & $92.93 \pm 3.550 \mathrm{a}$ & $4.58 \pm 0.033 \mathrm{a}$ & $52.28 \pm 1.697 \mathrm{a}$ & $199 \pm 5.187 \mathrm{ab}$ & $2.62 \pm 0.084 \mathrm{a}$ \\
10 & $93.33 \pm 3.333 \mathrm{a}$ & $100 \pm 0.000 \mathrm{a}$ & $4.45 \pm 0.040 \mathrm{a}$ & $48.43 \pm 1.933 \mathrm{a}$ & $217 \pm 8.686 \mathrm{ab}$ & $2.93 \pm 0.148 \mathrm{a}$ \\
20 & $90.00 \pm 0.000 \mathrm{a}$ & $96.67 \pm 3.333 \mathrm{a}$ & $4.53 \pm 0.047 \mathrm{a}$ & $50.00 \pm 0.519 \mathrm{a}$ & $191 \pm 18.097 \mathrm{~b}$ & $2.76 \pm 0.045 \mathrm{a}$ \\
50 & $96.67 \pm 3.333 \mathrm{a}$ & $104 \pm 7.033 \mathrm{a}$ & $4.50 \pm 0.058 \mathrm{a}$ & $49.15 \pm 0.993 \mathrm{a}$ & $209 \pm 8.990 \mathrm{ab}$ & $2.83 \pm 0.050 \mathrm{a}$ \\
75 & $86.67 \pm 8.819 \mathrm{a}$ & $93.70 \pm 12.276 \mathrm{a}$ & $4.58 \pm 0.092 \mathrm{a}$ & $53.35 \pm 3.835 \mathrm{a}$ & $197 \pm 17.535 \mathrm{ab}$ & $2.60 \pm 0.228 \mathrm{a}$ \\
100 & $96.67 \pm 3.333 \mathrm{a}$ & $104 \pm 7.033 \mathrm{a}$ & $4.41 \pm 0.032 \mathrm{a}$ & $47.52 \pm 1.258 \mathrm{a}$ & $225 \pm 5.240 \mathrm{ab}$ & $3.01 \pm 0.055 \mathrm{a}$ \\
125 & $93.33 \pm 3.333 \mathrm{a}$ & $100 \pm 6.094 \mathrm{a}$ & $4.48 \pm 0.052 \mathrm{a}$ & $50.22 \pm 2.320 \mathrm{a}$ & $217 \pm 8.288 \mathrm{ab}$ & $2.82 \pm 0.165 \mathrm{a}$ \\
250 & $90.00 \pm 5.774 \mathrm{a}$ & $97.03 \pm 9.099 \mathrm{a}$ & $4.47 \pm 0.216 \mathrm{a}$ & $50.58 \pm 2.720 \mathrm{a}$ & $235 \pm 17.198 \mathrm{a}$ & $2.90 \pm 0.165 \mathrm{a}$ \\
500 & $93.33 \pm 3.333 \mathrm{a}$ & $100 \pm 0.000 \mathrm{a}$ & $4.49 \pm 0.048 \mathrm{a}$ & $50.47 \pm 2.084 \mathrm{a}$ & $214 \pm 7.480 \mathrm{ab}$ & $2.80 \pm 0.142 \mathrm{a}$ \\
\hline $\mathrm{p}$-value & 0.761 & 0.937 & 0.798 & 0.644 & 0.239 & 0.444 \\
\hline
\end{tabular}




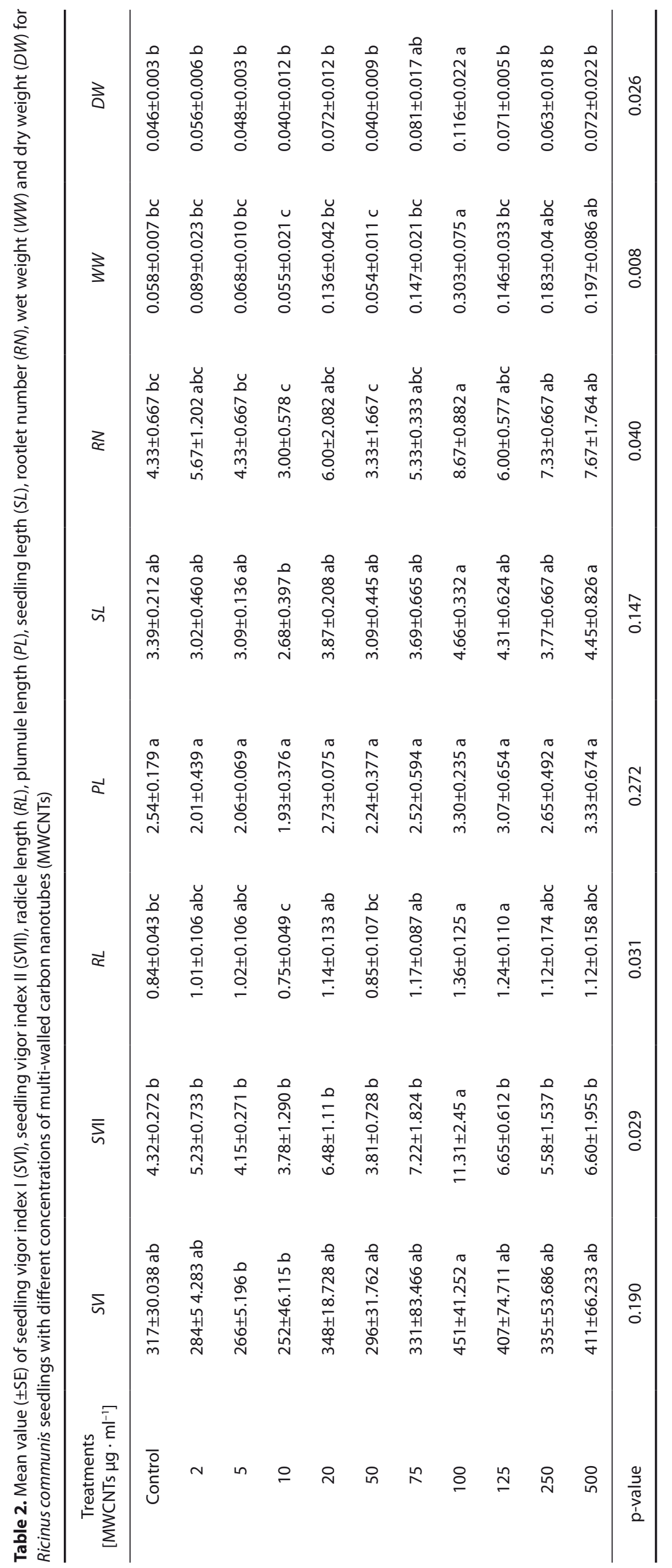


concentration of $10 \mu \mathrm{g} \cdot \mathrm{ml}^{-1}$, there was a significant increase (Fig. 4).

Carbon nanotubes with $100 \mu \mathrm{g} \cdot \mathrm{ml}^{-1}$ concentration led to a significant increase in the wet weight of castor seedlings in comparison with the control and concentrations of $2-125 \mu \mathrm{g} \cdot \mathrm{ml}^{-1}$.

The dry weight of seedlings in the same concentration demonstrated a significant increase in comparison with the control and all the concentrations used except $75 \mu \mathrm{g} \cdot \mathrm{ml}^{-1}$ (Table 2 ).

The maximum increase of seedling vigor index I under the treatment of MWCNTs was seen in the concentration $100 \mu \mathrm{g} \cdot \mathrm{ml}^{-1}$ and in comparison with concentrations of 5 and $10 \mu \mathrm{g} \cdot \mathrm{ml}^{-1}$, there was a significant increase. The other concentrations did not show any significant difference with the control and the concentration of $100 \mu \mathrm{g} \cdot \mathrm{ml}^{-1}$. Seedling vigor index II also increased in the concentration of $100 \mu \mathrm{g} \cdot \mathrm{ml}^{-1}$ MWCNTs and in comparison with the control and the other concentrations, this increase was significant (Table 2).

The response index $(R I)$ of the seedling factors is presented in Table 3. In all factors related to seedling growth, the negative amount of this index in 10 and $50 \mu \mathrm{g} \cdot \mathrm{ml}^{-1}$ concentrations of carbon nanotubes showed an inhibitory effect of the treatment used.

In the germination factor, the response index of GI in the concentration of $250 \mu \mathrm{g} \cdot \mathrm{ml}^{-1}$ and response index of WGI in concentrations of 2 and $100 \mu \mathrm{g} \cdot \mathrm{ml}^{-1}$ and $M G T$ in all concentrations was positive, demonstrating a stimulatory effect. The response index of GP in concentrations of 5, 20, 75 and $250 \mu \mathrm{g} \cdot \mathrm{ml}^{-1}$, and $G R$ in concentrations of 2 and $10 \mu \mathrm{g} \cdot \mathrm{ml}^{-1}$ were negative which demonstrated an inhibitory effect (Table 4).
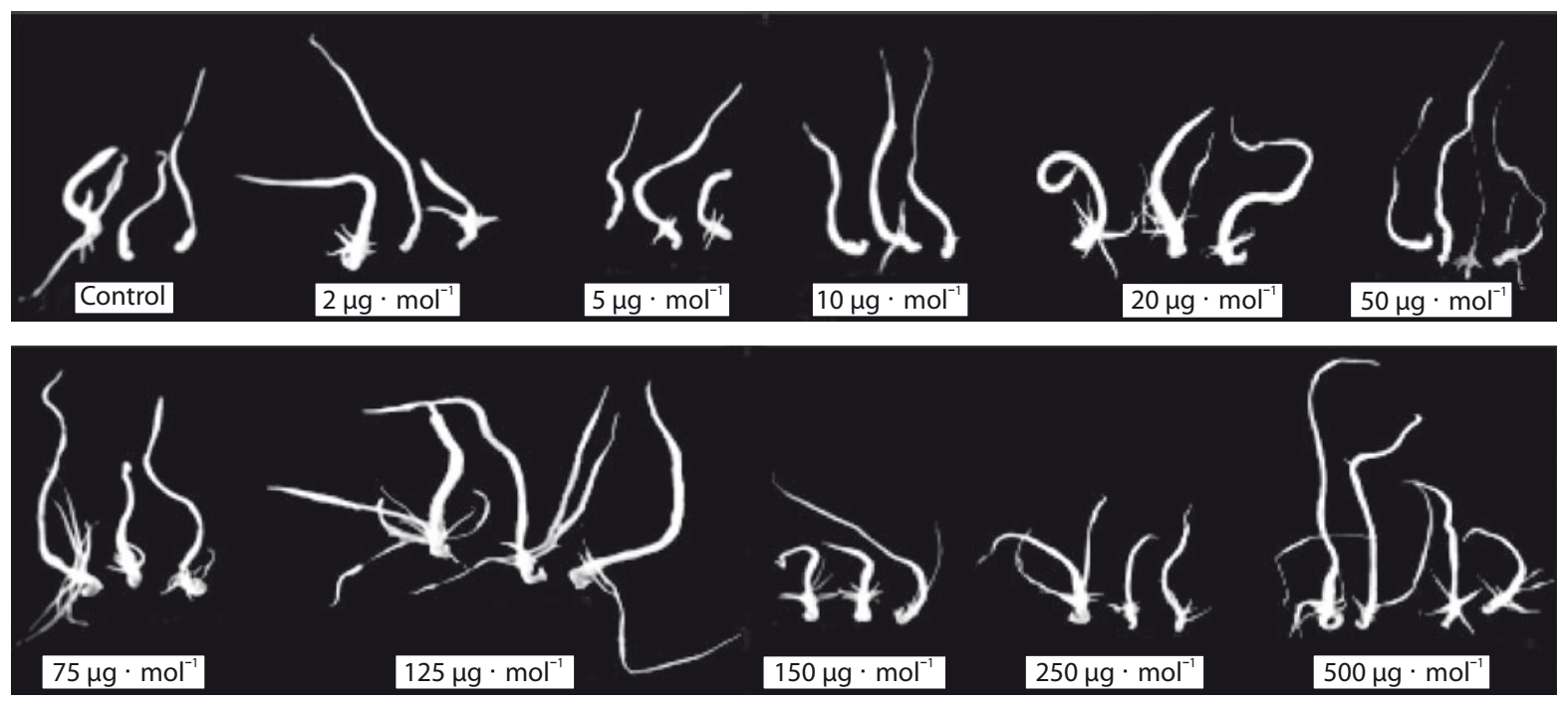

Fig. 4. Effects of multi-walled carbon nanotubes (MWCNTs) on root and shoot elongation of castor seedlings

Table 3. Response index $(R I)$ with different concentrations of multi-walled carbon nanotubes (MWCNTs) on seed germination percent $(G P)$, mean germination time $(M G T)$, germination rate $(G R)$, germination index $(G l)$ and weighted germination index (WGl) of Ricinus communis

\begin{tabular}{|c|c|c|c|c|c|}
\hline $\begin{array}{c}\text { Treatments } \\
{\left[\text { MWCNTs } \mu \mathrm{g} \cdot \mathrm{ml}^{-1}\right]}\end{array}$ & $R I-G P$ & RI-MGT & $R I-G R$ & $R I-G I$ & $R I-W G I$ \\
\hline 2 & 0 & 0.02 & -0.03 & -0.001 & 0.001 \\
\hline 5 & -0.07 & 0.05 & 0.06 & -0.5 & -0.112 \\
\hline 10 & 0 & 0.02 & -0.01 & -0.001 & -0.01 \\
\hline 20 & -0.036 & 0.04 & 0.02 & -0.5 & -0.095 \\
\hline 50 & 0.03 & 0.03 & 0.01 & -0.001 & -0.04 \\
\hline 75 & -0.07 & 0.05 & 0.08 & -0.5 & -0.12 \\
\hline 100 & 0.03 & 0.01 & -0.03 & -0.0002 & 0.02 \\
\hline 125 & 0 & 0.03 & 0.02 & -0.001 & -0.04 \\
\hline 250 & -0.036 & 0.02 & 0.03 & 0.0003 & -0.02 \\
\hline 500 & 0 & 0.03 & 0.03 & -0.001 & -0.05 \\
\hline
\end{tabular}


Table 4. Response index $(R I)$ with different concentrations of multi-walled carbon nanotubes (MWCNTs) on seedling vigor index I (SVI), seedling vigor index II (SVII), radicle length $(R L)$, plumule length $(P L)$, seedling length $(S L)$, rootlet number $(R N)$, wet weight $(W W)$ and dry weight (DW) on Ricinus communis seedlings

\begin{tabular}{ccccccccc}
\hline $\begin{array}{c}\text { Treatments } \\
\left.\text { [MWCNTs } \mu \mathrm{g} \cdot \mathrm{ml}^{-1}\right]\end{array}$ & $R I-S \mathrm{VI}$ & $R I-S \mathrm{VII}$ & $R I-R L$ & $R I-P L$ & $R I-S L$ & $R I-R N$ & $R I-W W$ & $R I-D W$ \\
\hline 2 & -0.3 & 0.17 & 0.17 & -0.2 & -0.11 & 0.24 & 0.35 & 0.18 \\
5 & -0.3 & -0.04 & 0.18 & -0.19 & -0.09 & 0 & 0.15 & 0.04 \\
10 & -0.3 & -0.125 & -0.11 & -0.24 & -0.21 & -0.31 & -0.05 & -0.14 \\
20 & 0.001 & 0.3 & 0.26 & 0.07 & 0.12 & 0.28 & 0.57 & 0.36 \\
50 & -0.3 & -0.12 & 0.01 & -0.12 & -0.09 & -0.24 & -0.07 & -0.13 \\
75 & 0.001 & 0.4 & 0.28 & -0.01 & 0.08 & 0.18 & 0.6 & 0.43 \\
100 & 0.25 & 0.62 & 0.38 & 0.23 & 0.27 & 0.5 & 0.8 & 0.6 \\
125 & 0.25 & 0.35 & 0.3 & 0.17 & 0.79 & 0.28 & 0.6 & 0.34 \\
250 & 0.001 & 0.23 & 0.25 & 0.04 & 0.1 & 0.41 & 0.7 & 0.27 \\
500 & 0.001 & 0.35 & 0.25 & 0.24 & 0.24 & 0.44 & 0.7 & 0.36 \\
\hline
\end{tabular}

\section{Discussion}

Germination, as a critical process in the lifecycle of plants, includes the transition of stored food into the seedling, and the start of metabolic and growth activities (Almasouri et al. 2001). Based on the results of several studies, it is known that different nanoparticles have both positive and negative effects on plant seedlings and their growth (Krishnaraj et al. 2012). Carbon nanotubes act as regulators of plant seedlings and growth (Lahiani et al. 2013) and lead to increased humidity levels of the seeds (Kole et al. 2013). They can induce seed germination by penetrating into the seed cover (Pourkhaloee et al. 2011). The effect of MWCNTs on the seed germination of Brassica juncea $\mathrm{L}$. and Phaseolus mungo L. plants was $100 \%$, which indicated their safety for seed germination (Ghodake et al. 2010). The effect of carbon nanotubes on the germination and growth of plants confirms the penetration of materials into the thick seed cover and their entrance into cellular space and participation in the processes of water absorption, leading to improved germination and growth of plants (Khodakovskaya et al. 2009; Ghodake et al. 2010). MWCNTs, by penetrating into the seed cover, stimulated the growth of tomato and mustard seeds. It has also been demonstrated that MWCNTs can penetrate the thick cover of wheat, corn, peanut, and garlic seeds, thereby leading to absorption of water into the seeds - this was effective on growth at lower concentrations (Srivastava and Rao 2014). The ability of single wall carbon nanotubes to penetrate into the walls and membranes of tobacco cells has been shown (Liu et al. 2009). Exposure of seeds, such as tomato, to the carbon nanotubes could increase the germination percentage and growth of seedlings (Khodakovskaya et al. 2009). MWCNTs have an effect on the growth of tobacco cells in the medium over a wide range of concentrations $\left(5-500 \mu \mathrm{g} \cdot \mathrm{ml}^{-1}\right)$ in such a way that a low concentration of $5 \mu \mathrm{g} \cdot \mathrm{ml}^{-1}$ had a stimulatory effect, while higher concentrations $\left(100-500 \mu \mathrm{g} \cdot \mathrm{ml}^{-1}\right)$ had an inhibitory effect (Khodakovskaya et al. 2012). Nevertheless, in the present study, in the most frequently studied indexes, higher concentrations, up to an optimum level, increased seedling growth and germination. Onobrychis arenaria (Kit.) DC seedlings treated with MWNTs showed an increased germination rate (Smirnova et al. 2011) that can be due to the positive role of carbon nanotubes in absorption of water (Kole et al. 2013). The growth of the roots and stems of $O$. arenaria seedlings is stimulated with MWNTs treatment (Smirnova et al. 2011). MWNTs were found in the cells, root tissues, and the leaves of seedlings due to the ability of MWNTs to penetrate and accumulate in the root and be transferred through the vascular system from the root to the stem and to the leaves of seedlings. Seed germination is activated with the sedimentation of MWCNTs on the surface of corn, barley, and soybean seeds (Lahiani et al. 2013). In this study, the germination percentage increased only in concentrations of 50 and $100 \mu \mathrm{g} \cdot \mathrm{ml}^{-1}$. In comparison with the control, there was no significant difference. Watersoluble MWCNT (wsMWCNT) had a significant effect on the growth of Cicer arietinum L. plants (Tripathi et al. 2011). The germination rate of corn and rye plants treated with MWCNT was reduced, while the root length was increased (Begum et al. 2012, 2014). In the present study, in the concentration of $2 \mu \mathrm{g} \cdot \mathrm{ml}^{-1}$, 
the germination percentage increased, quite similar to the control, and the radicle length, in comparison with the control, increased as well. MWCNT increased the wet weight and the length of the wheat seedling roots, but it had no effect on seed germination and stem length (Wang et al. 2012; Tiwari et al. 2014). In the present study, carbon nanotubes had no effect on the germination of castor seeds and the length of plumule. But root length and wet weight in the treatment of $100 \mathrm{mg} \cdot \mathrm{ml}^{-1}$ showed a significant increase in comparison with the control. Germination and the growth of four plant species (Lycopersicum esculentum Mill. cv. 'Falcato'), onion (Allium cepa L. cv. 'Yellow Sweet Spanish'), turnip (Brassica rapa L. cv. 'Toria'), and radish (Raphanus sativus L. cv. 'Small radish) in MWCNT concentrations of $0,10,20$, and $40 \mathrm{mg} \cdot \mathrm{ml}^{-1}$, respectively, demonstrated that carbon nanotubes in concentrations of $10-40 \mathrm{mg} \cdot \mathrm{ml}^{-1}$ enhance the germination of onion and tomato better than that of turnip and radish. However, these concentrations do not change the germination and growth rates of turnip (Haghighi and Teixeira da Silva 2014). In this study, the germination of castor seeds was not affected by carbon nanotubes, while the growth of castor seedlings was improved at higher concentrations.

Accordingly, changes in the physiological components of plants do not occur only by absorbing MWCNTs on the surface of roots, but also by penetration, absorption, and accumulation in the plant cells (Smirnova et al. 2011). The present study demonstrates the nonsignificant effect of different concentrations of MWCNTs on the germination stage of castor seeds, while in the growth stage of seedlings, significant effects were seen especially in the number of rootlets, wet and dry weight of seedlings, and the seedling vigor index. We have shown that the germination of castor seedlings is affected by the MWCNT in a concentration-dependent manner. Lower concentrations are beneficial, while higher ones prove to be relatively detrimental.

The results obtained from this study showed a stimulatory effect of MWCNTs on the biomass and root growth of castor seedlings, especially at a concentration of $100 \mu \mathrm{g} \cdot \mathrm{ml}^{-1}$. The possible mechanism for which the concentration-dependent MWCNTs affect the growth of castor seedlings needs to be clarified, since the inhibitory effect of 10 and $50 \mu \mathrm{g} \cdot \mathrm{ml}^{-1}$ MWCNTs and the stimulatory effect of MWNTs on the biomass and root growth of castor seedlings, especially at a concentration of $100 \mu \mathrm{g} \cdot \mathrm{ml}^{-1}$. Tripathi et al. (2011) have shown that MWCNT aligned themselves in the vascular bundles of the roots of gram plants and enhanced plant water uptake, possibly by the ensuing channeling action. It is possible then that the enhanced water uptake and the orderliness of the behavior consequent to higher concentrations of MWCNT application might also result from a similar alignment and channeling in contrast to the normal random thermal motion of the water molecules in the lower concentrations. Also, the mechanism behind the stimulatory effect of MWCNTs on the growth of castor seedlings in this study is that the mentioned compounds can support the absorption of water by the seeds. Probably, carbon nanotubes can penetrate the thick seed coat and support the water uptake inside seeds. MWCNTs penetrate the cell wall and accumulate in the cells and tissues, and, via the vascular system, they are transferred from the root to the stem and to the leaf of the seedling (Srivastava and Rao 2014). Lower concentrations are beneficial as they increase the growth indexes and water content of the morphological parts, most prominently for the root, that are directly in contact with the medium (Srivastava and Rao 2014). The activated process of water uptake could be responsible for the significantly faster germination rates and higher biomass production for the plants that were exposed to carbon nanotubes. Molecular mechanisms of CNT-induced water uptake inside seeds are not clear and require further investigation. However, the positive effect of CNTs on seed germination could have significant economic importance for agriculture, horticulture, and the energy sector, such as the production of biofuels (Khodakovskaya et al. 2009). The positive effects of MWNTs on germination are of economic importance to farmers (Smirnova et al. 2011). Furthermore, it seems that applying carbon nanotubes can effectively improve the seedling growth process. This stimulatory effect can have an important role on their application in the modelling of the plants' function.

\section{References}

Almasouri M., Kinet J.M., Lutts S. 2001. Effect of salt and osmotic stresses on germination in durum wheat (Triticum durum Desf). Plant and Soil 231 (2): 243-254.

Begum P., Ikhtiari R., Fugetsu B., Matsuoka M., Akasaka T., Watari F. 2012. Phytotoxicity of multi-walled carbon nanotubes assessed by selected plant species in the seedling stage. Applied Surface Science 262: 120-124. DOI: https:// doi.org/10.1016/j.apsusc.2012.03.028

Begum P., Ikhtiari R., Fugetsu B. 2014. Potential impact of multi-walled carbon nanotubes exposure to the seedling stage of selected plant species. Nanomaterials 4 (2): 203-221. DOI: 10.3390/nano4020203

Bu H.Y., Chen X.L., Wang Y.F., Xu X.L., Liu K., Du G.Z. 2007a. Germination time, other plant traits and phylogeny in an alpine meadow on the eastern Qinghai-Tibet Plateau. Community Ecology 8 (2): 221-227. DOI: 10.1556/ ComEc.8.2007.2.8.

Bu H.Y., Chen X.L., Xu X.L., Liu K., Jia P., Du G.Z. 2007b. Seed mass and germination in an alpine meadow on the eastern Tsinghai-Tibet plateau. Plant Ecology 191 (1): 127-149. DOI: 10.1007/s11258-006-9221-5.

Bu H.Y., Du G.Z., Chen X.L., Xu X.L., Liu K., Wen S.J. 2008. Community-wide germination strategies in an alpine meadow on the eastern Qinghai-Tibet plateau: phylogenetic and life-history correlates. Plant Ecology 195 (1): 87-98. DOI: 10.1007/s11258-007-9301-1. 
Bu H.Y., Du G.Z., Chen X.L., Wang Y.F., Xu X.L., Liu K. 2009. The evolutionary significance of seed germinability in an alpine meadow on the eastern Qinghai-Tibet Plateau. Arctic, Antarctic and Alpine Research 41: 97-102. DOI: 10.1657/1523-0430-41.1.97

Figueroa J.A., Armesto J.J. 2001. Community-wide germination strategies in a temperate rainforest of Southern Chile: ecological and evolutionary correlates. Australian Journal of Botany 49 (4): 411-425. DOI: 10.1071/BT00013.

Ghodake G., Seo Y.D., Park D., Lee D.S. 2010. Phytotoxicity of carbon nanotubes assessed by Brassica juncea and Phaseolus mungo. Journal of Nanoelectronics Optoelectronics 5 (2): 157-160. DOI: 10.1166/jno.2010.1084

Haghighi M., da Silva T.J.A. 2014. The effect of carbon nanotubes on the seed germination and seedling growth of four vegetable species. Journal of Crop Science and Biotechnology 17 (4): 201-208. DOI No. 10.1007/s12892-014-0057-6

Kandil A.A., Sharief A.E., Ahmed Kh.R. 2015. Performance of some soybean Glycine max (L.) Merrill. cultivars under salinity stress to germination characters. International Journal of Agronomy and Agricultural Research 6 (3): 48-56.

Khan A., Sanwal M. 2015. Medicinal importance of Ricinus communis (Arandi). International Journal of Current Trends in Pharmaceutical Research 3 (3): 868-941.

Khodakovskaya M., Dervishi E., Mahmood M., Xu Y., Li Z., Watanabe F., Biris A.S. 2009. Carbon nanotubes are able to penetrate plant seed coat and dramatically affect seed germination and plant growth. American Chemical Society 3 (10): 3221-3227. DOI: $10.1021 / \mathrm{nn} 302965 \mathrm{w}$

Khodakovskaya M.V., de Silva K., Biris A.S., Dervishi E., Villagarcia H. 2012. Carbon nanotubes induce growth enhancement of tobacco cells. American Chemical Society Nano 6 (3): 2128-2135. DOI: $10.1021 / \mathrm{nn} 204643 \mathrm{~g}$

Kole C., Kole P., Randunu K.M., Choudhary P., Podila R., Ke P.C., Rao A.M., Marcus R.K. 2013. Nanobiotechnology can boost crop production and quality: first evidence from increased plant biomass, fruit yield and phytomedicine content in bitter melon (Momordica charantia). BMC Biotechnology. DOI: 10.1186/1472-6750-13-37.

Krishnaraj C., Jagan E.G., Ramachandran R., Abirami S.M., Mohan N., Kalaichelvan P.T. 2012. Effect of biologically synthesized silver nanoparticles on Bacopa monnieri (Linn.) Wettst. plant growth metabolism. Process Biochemistry 47 (4): 51-658. DOI: https://doi.org/10.1016/j. procbio.2012.01.006

Lahiani M.H., Dervishi E., Chen J., Nima Z., Gaume A., Biris A.S., Khodakovskaya M.V. 2013. Impact of carbon nanotube exposure to seeds of valuable crops. American Chemical Society, Applied Materials and Interfaces 5 (16): 7965-7973. DOI: $10.1021 / \mathrm{am} 402052 \mathrm{x}$

Liu Q., Chen B., Wang Q., Shi X., Xiao Z., Lin J., Fang X. 2009. Carbon nanotubes as molecular transporters for walled plant cells. Nano Letters 9 (3):1007-1010. DOI: 10.1021/ nl803083u.

Ma X., Geiser-Lee J., Deng Y., Kolmakov A. 2010. Interactions between engineered nanoparticles(ENPs) and plants: Phy- totoxicity, uptake and accumulation. Science of the Total Environment 408 (16): 3053-3061. DOI: https://doi. org/10.1016/j.scitotenv.2010.03.031

Mani U., Dhanasingh S., Arunachalam R., Paul E., Shanmugam P., Rose C., Baran Mandal A. 2013. A simple and green method for the synthesis of silver nanoparticles using Ricinus communis leaf extract. Progress in Nanotechnology and Nanomaterials 2 (1): 21-25.

Milne W.I., Teo K.B.K., Amaratunga G.A.J., Legagneux P., Gangloff L., Schnell J.P., Semet V., Binh V.T., Groening O. 2004. Carbon nanotubes as field emission sources. Journal of Materials of Chemistry 14: 933-943. DOI: 10.1039/B314155C

Nel A., Xia T., Meng H., Wang X., Lin S., Ji Z., Zhang H. 2013. Nanomaterial toxicity testing in the 21st century: use of a predictive toxicological approach and high-throughput screening. Accounts of Chemical Research 46 (3): 607-621. DOI: $10.1021 / \mathrm{ar} 300022 \mathrm{~h}$.

Pourkhaloee A., Haghighi M., Saharkhiz M.J., Jouzi H., Doroodmand M.M. 2011. Carbon nanotubes can promote seed germination via seed coat penetration. Journal of Seed Technology 33 (2): 155-169.

Prakash E., Gupta D.K. 2014. In vitro study of extracts of Ricinus communis Linn on human cancer cell lines. Journal of Medical Sciences and Public Health 2 (1): 15-20.

Smirnova E.A., Gusev A.A., Zaitseva O.N., Lazareva E.M., Onishchenko G.E., Kuznetsova E.V., Tkachev A.G., Feofanov A.V., Kirpichnikov M.P. 2011. Multi-walled carbon nanotubes penetrate into plant cells and affect the growth of Onobrychis arenaria seedlings. Acta Naturae 3 (1): 8.

Srivastava A., Rao D.P. 2014. Enhancement of seed Germinarion and plant growth of Whest, Maize, Peanut and Garlic using Multiwalled carbon nanotubes, Enhancement of plant growth using multiwalled carbon nanotubes. European Chemical Bulletin 3 (5): 502-504.

Tang Y., Shang Z.H., Li X.L., Ma Y.S., Wu H.Y., Long R.J. 2008. Allelopathic effects of Aerbalupulin on several graminaceous grass species on alpine meadow. Chinese Journal of Ecology 27: 2067-2072.

Tripathi S., Kumar Sonkar S., Sarkar S. 2011. Growth stimulation of gram (Cicer arietinum) plant by water soluble carbon nanotubes. Nanoscale 3 (3): 1176. DOI: 10.1039/c0nr00722f.

Tiwari D.K., Dasgupta-Schubert N., Villasenor Cendejas L.M., Villegas J., Carreto Montoya L., Borjas García S.E. 2014. Interfacing carbon nanotubes (CNT) with plants: enhancement of growth, water and ionic nutrient uptake in maize (Zea mays) and implications for nanoagriculture. Applied Nanoscience 4 (5): 577-591. DOI: https://doi.org/10.1007/ s13204-013-0236-7

Wang X., Han H., Liu X., Gu X., Chen K., Lu D. 2012. Multiwalled carbon nanotubes can enhance root elongation of wheat (Triticum aestivum) plants. Journal of Nanoparticle Research 14: 841-851. DOI: 10.1007/s11051-012-0841-5

Wu G.L., Du G.Z. 2008. Germination is related to seed mass in grasses (Poaceae) of the eastern Qinghai-Tibetan Plateau, China. Nordic Journal of Botany 25 (5-6): 361-365. DOI: 10.1111/j.0107-055X.2007.00179.x 